\title{
Motivational Profiles of Medical Students of Nepalese Army Institute of Health Sciences
}

\author{
Lochana Shrestha, ${ }^{1}$ Shambhu Nath Pant ${ }^{1}$ \\ ${ }^{1}$ Department of Community Medicine Nepalese Army Institute of Health Science, Kathmandu, Nepal.
}

\begin{abstract}
Background: Students enter the medical study with different types of motives. Given the importance of academic motivation for good academic achievement of the students, the present study was designed to reveal the possible relationship between academic motivation and achievement in medical students.

Methods: In this cross-sectional study medical students (N=364) of Nepalese Army institute of Health Sciences were participated and classified to different subgroups using intrinsic and controlled motivation scores. Cluster membership was used as an independent variable to assess differences in study strategies and academic performance.

Results: Four clusters were obtained: High Intrinsic High Controlled, Low Intrinsic High Controlled, High Intrinsic Low Controlled, and Low Intrinsic Low Controlled. High Intrinsic High Controlled and High Intrinsic Low Controlled profile students constituted $36.1 \%, 22.6 \%$ of the population, respectively. No significant differences were observed as regards to deep strategy and surface strategy between high interest status motivated and high interest-motivated students. However, both of the clusters had significantly deeper, surface strategy and better academic performance than status-motivated and low-motivation clusters $(\mathrm{p}<0.001)$.

Conclusions: The interest status motivated and interest-motivated medical students were associated with good deep and surface study strategy and good academic performance. Low-motivation and status-motivated students were associated with the least academic performance with less interest learning behaviors. This reflected that motivation is important required component for good learning outcomes for medical students

Keywords: Academic performance; controlled motivation; clusters; intrinsic motivation; motivation.
\end{abstract}

\section{INTRODUCTION}

Students enrolled in medical study with different types of motives. These could be generated internally or from external factors. According to Self Determination Theory (SDT), intrinsic motivation is seen when an activity is carried out of genuine interest, and controlled motivation is seen when an activity is carried out with external factors influence. ${ }^{1,2}$ To know how the students give quality efforts for study and their performance in medical school, these types of motivation endorsed by the students are considered important. Psychologists have emphasized the significance of motivation in gaining knowledge, learning new skills, strategies, and behavior. ${ }^{3}$

We aimed to find out four types of motivational profile of students, those are High Intrinsic high control(HIHC), High intrinsic low control(HILC), Low intrinsic low controlled (LILC), Low intrinsic high controlled (LIHC) and their relationship with students' academic achievement. ${ }^{4}$

The present study was designed to find out the possible relationship between academic motivation and achievement in medical students.

\section{METHODS}

This cross sectional study was conducted among $2^{\text {nd }}$ to $5^{\text {th }}$ year final medical students of Nepalese Army Institute of Health sciences (NAIHS) on September 2016.

Under Structural Equation Modeling (SEM) the ideal rule for a good sample size is more than 200 , a more accurate estimation being 20 subjects for every variable in the model. Our respondents size is 346 which is satisfied both rules. 5,6

The students were explained about their voluntary

Correspondence: Prof Dr Lochana Shrestha, Department of Community Medicine, DOI: http://dx.doi.org/10.3126/ Nepalese Army Institute of Health Science (NAIHS), Kathmandu, Nepal. Email: inhrc.v15i3.18850 lochanashrestha@gmail.com, Phone: 977-9841281688. 
participation in the study, guarantee of confidentiality and anonymity and that non-participation would not cause them any harm. We received ethical approval from ethical board of the medical institute.

We developed questionnaire which include personal data, social cultural factors, the Academic Motivation Scale $(A M S)^{7}$ for the measurement of intrinsic and controlled motivation. We used modified AMS, which was designed for college and university students, for use in medical students. ${ }^{8}$ Questionnaire also include Study Process Questionnaire (SPQ) ${ }^{9}$ for the assessment of the study strategies (deep and surface). The strategy that used by the student to "maximize meaning" in the material learnt is deep strategy and Surface Strategy apply to note learning or memorization of facts.

To calculate the intrinsic motivation scores, we took an average of the scores on the three subscales of intrinsic motivation from the $\mathrm{AMS}^{7}$ and for controlled motivation scores, we took an average of introjected regulation and external regulation extrinsic motivation scores as described in SDT literature.

The criterion for academic achievement was chosen the score of first year result as everybody has gone through this exam. Questionnaire was pretested to see whether students understand and complete with one brain. On one day medical students of second, third, fourth and fifth year, in separate classrooms were asked to complete the questionnaire without making consultation among them. This is done to take individual own view to mitigate subject bias.

For the basic analysis the software programme SPSS version 22.0 was used. Based on the Z-scores of intrinsic and controlled motivation scores of medical students, they were clustered into different motivational profiles Once the four motivational profiles were made, the variances in intrinsic and controlled motivation scores explained by clustered groups were calculated using analysis of variance ANOVA. We computed correlation coefficient between all independent and dependent variables to study the degree and direction of the relationship between them. We took cluster membership as independent variables and learning variables and outcomes as independent variable conducting MANCOVA.

\section{RESULTS}

There was a response rate of $76.9 \%$ since 346 students out of 450 filled out the survey. Out of these $65.6 \%$ were males and $34.4 \%$ females (Table 1 ). The median age of participating students in the sample were 22.0 years and the range $(19-26)$ years. Ethnic composition of students was found largely Chhetry (39.1\%), Brahmin (32.6\%) and Newar (13.8\%) and rests others (15.0\%). Parents' education status showed a majority of them were having higher education (father $72.2 \%$, mother $44.4 \%$ ). The distribution of students by father's occupation indicated a majority of them in service $(68.0 \%)$ followed by business (24.1\%) and agriculture (7.8\%). Mother's occupation showed majority as housewife (56.3\%) while others in service $(27.2 \%)$, business $(10.7 \%)$ and agriculture $(5.8 \%)$. Table 1. Characteristics of Medical students.

\begin{tabular}{|c|c|c|}
\hline Description & No. & $\%$ \\
\hline 1. Respondents & 346 & 75.4 \\
\hline \multirow[t]{2}{*}{ 2. Gender: } & 227 & 65.6 \\
\hline & 119 & 34.4 \\
\hline 3. Age (years): Mean & 21.7 & \\
\hline Median & 22 & \\
\hline Range & $19-26$ & \\
\hline 4. Ethnicity: Brahmin & 111 & 32.6 \\
\hline Chettry & 133 & 39.1 \\
\hline Newar & 47 & 13.8 \\
\hline Others & 49 & 14.4 \\
\hline $\begin{array}{l}\text { 5.1 Father Education } \\
\text { Primary }\end{array}$ & 25 & 7.7 \\
\hline Secondary & 65 & 20.1 \\
\hline Higher & 234 & 72.2 \\
\hline $\begin{array}{l}5.2 \text { Mother Education } \\
\text { Primary }\end{array}$ & 71 & 21.5 \\
\hline Secondary & 113 & 34.1 \\
\hline Higher & 147 & 44.4 \\
\hline $\begin{array}{l}\text { 6.1Father Occupation } \\
\text { Business }\end{array}$ & 71 & 24.1 \\
\hline Service & 217 & 68 \\
\hline Agriculture & 25 & 7.8 \\
\hline $\begin{array}{l}6.2 \text { Mother Occupation } \\
\text { Business }\end{array}$ & 35 & 10.7 \\
\hline Service & 89 & 27.2 \\
\hline Agriculture & 19 & 5.8 \\
\hline Housewife & 184 & 56.3 \\
\hline \multicolumn{3}{|c|}{ 7. Influence to study medicine } \\
\hline Yes & 178 & 51.4 \\
\hline No & 168 & 48.6 \\
\hline
\end{tabular}

178 out of 346 students (51.4\%) had a prior influence to study medicine mainly from their parents and relatives (95.5\%) and a few from others (4.5\%). The decision by students as why to study medicine had multiple responses (Table 2). Out of total responses, majority of responses were to contribute to the welfare of the society (38.6\%) 
and were followed by self-achievement $(37.6 \%)$, social recognition $(15.2 \%)$, and as vocation and others $(6.6 \%)$.

Table 2. Reasons for enrollment in medical education

\begin{tabular}{lrr} 
Reasons & No. & $\%$ \\
\hline Contribute to welfare of society & 152 & 38.6 \\
\hline Self-achievement & 148 & 37.6 \\
\hline Social recognition & 60 & 15.2 \\
\hline Vocation & 12 & 3 \\
\hline Others & 22 & 3.6 \\
\hline
\end{tabular}

Analysis of the learning variables and outcomes with respective completed responses carried out as the students did not fill out some of the items in given questionnaire. The mean and standard deviation on all variables by gender are worked out to examine the significance difference if any between male and female with p-values. In addition, it shows the correlations between different variables (Table 3 ).

Intrinsic motivation found to be significantly positively correlated with deep strategy $(r=0.236)$ and surface strategy $(r=0.265)$ towards study and academic performance $(r=0.198)$. The controlled motivation relatively less significantly positively correlated with deep strategy $(r=0.130)$ and surface strategy $(r=$ 0.112 ) than intrinsic motivation. The mixed strategy towards study seem to have a negative correlation with intrinsic motivation $(r=-0.163)$ but to an extent it is positively correlated with controlled motivation. Surface strategy towards study is positively correlated to academic performance $(r=0.072)$ whereas mixed strategy is negatively correlated with it $(r=-0.182)$. The intrinsic motivation was high among female than male and this difference was statistically significant. $(p=0.05)$ Academic performance is highly significant in females than in males $(p=0.011)$.

All the scores of learning and outcome variables from students were converted into Z-scores in order to make them comparable. The students were clustered into four different motivational profiles from high to low motivation spectrum based on the Z-scores on intrinsic motivation and controlled motivation.

The four clusters situation has explained $50.3 \%$ variance in the intrinsic motivational scores and $61.2 \%$ variation in controlled motivational scores. The four cluster situation is shown in Table 4. The mean scores and standard deviation (SD) for intrinsic and controlled motivation varies by clusters. The intrinsic motivational score has consistently been on decrease from HIHC to LILC clusters with coefficient of variation (CV) ranging from $7.3 \%$ to $12.8 \%$. In contrast, the controlled motivation showed a slightly different picture in a sense that HIHC and LIHC cluster scores are similar with CVs $8.2 \%$ to $7.1 \%$, HILC and LILC cluster scores though being lower than HIHC, are almost same with CVs between $15.6 \%$ to $15.8 \%$. The distribution of students in four different motivational profiles show HIHC comprised of $36.1 \%$ of total students, HILC $22.6 \%$, LIHC $17.6 \%$ and LILC $23.8 \%$. The distribution of males and females in different clusters found to be not significantly different $(p=0.69)$.

Performing MANCOVA using four cluster membership as independent variables, learning variables and outcomes as dependent variables, this study attempt to analyze the differences between learning variables and outcomes between the clusters. (Table 5).F-values and eta-squared for dependent variables were found to be highly significant $(p<0.016)$ which mean the learning variables and outcomes are significantly different for different motivational profiles of students.

The deep strategy towards study was found to be at different levels for different clusters. No significant differences were observed as regards to deep strategy towards study between interest-status motivated (HIHC) and interest-motivated (HILC) students despite the later at slightly higher level. $(p=0.695)$

However, both clusters had significantly more deep strategy compared to low motivation (LILC) cluster of students $(p<0.001)$. As regards to surface strategy by clusters, no significant differences were observed between HIHC and HILC motivational profiles but both of them had significantly more surface strategy than status-motivated (LIHC) and low-motivation (LILC) students clusters $(p<0.001)$.

The academic performance in terms of mean and standard deviations of percentage marks for different clusters were as presented in Table 5. No significant differences in academic performance were observed between interest-status motivated $(\mathrm{HIHC})$ and interestmotivated (HILC) students, $(p=0.749)$ and also between status-motivated and low-motivation students ( $p=0.267)$. However, in this regard there is significant difference between HIHC in compare to LILC and LIHC. Also HILC clusters comprise of increase academic performance than others.

\section{DISCUSSION}




\begin{tabular}{|c|c|c|c|c|c|c|c|c|c|c|c|}
\hline \multirow[t]{2}{*}{ Variables } & \multicolumn{2}{|c|}{ Males } & \multicolumn{2}{|c|}{ Females } & \multirow{2}{*}{$\begin{array}{l}\text { t-test } \\
\text { (p-value) }\end{array}$} & \multirow[t]{2}{*}{1} & \multirow[t]{2}{*}{2} & \multirow[t]{2}{*}{3} & \multirow[t]{2}{*}{4} & \multirow[t]{2}{*}{5} & \multirow[t]{2}{*}{6} \\
\hline & Mean & SD & Mean & SD & & & & & & & \\
\hline $\begin{array}{l}\text { 1. Intrinsic } \\
\text { motivation }\end{array}$ & 3.95 & 0.49 & 4.05 & 0.46 & 0.05 & - & & & & & \\
\hline $\begin{array}{l}\text { 2. Controlled } \\
\text { motivation }\end{array}$ & 3.63 & 0.67 & 3.64 & 0.65 & 0.842 & $0.317^{* *}$ & - & & & & \\
\hline 3. Deep strategy & 2.94 & 0.53 & 2.87 & 0.57 & 0.268 & $0.236^{* *}$ & $0.130^{*}$ & - & & & \\
\hline $\begin{array}{l}\text { 4. Surface } \\
\text { strategy }\end{array}$ & 3.15 & 0.63 & 3.08 & 0.65 & 0.394 & $0.265^{* *}$ & $0.112^{*}$ & $0.512^{* *}$ & - & & \\
\hline 5. Mixed strategy & 2.43 & 0.66 & 2.4 & 0.7 & 0.715 & -0.163 & 0.063 & $0.332^{* *}$ & $0.208^{* *}$ & - & \\
\hline $\begin{array}{l}\text { 6. Academic } \\
\text { performance }\end{array}$ & 65.71 & 4.93 & 67.25 & 4.9 & 0.011 & $0.198^{* *}$ & 0.016 & 0.036 & 0.072 & -0.182 & \\
\hline \multicolumn{11}{|c|}{${ }^{*} p<0.05,{ }^{* *} p<0.01$} & \\
\hline
\end{tabular}

Table 4. Distribution of students among the 4 clusters / profiles along with the gender distribution.

Cluster membership

1. Intrinsic motivation

- Mean 4

HIHC

HILC

LIHC

LILC

$\begin{array}{lllll}4.29 & 4.19 & 3.69 & 3.53 & 3.98 \\ 0.3 & 0.26 & 0.37 & 0.42 & 0.46\end{array}$

2. Controlled motivation

$\begin{array}{llllll}\text { - Mean } & 4.13 & 3.09 & 4.04 & 3.09 & 3.63 \\ \text { - SD } & 0.34 & 0.48 & 0.29 & 0.49 & 0.65\end{array}$

\begin{tabular}{|lrrrrr}
\hline 3. No. of students in the cluster (\%) & $123(36.1)$ & $77(22.6)$ & $60(17.6)$ & $81(23.8)$ & $341(100.0)$ \\
\hline Males & $79(35.1)$ & $48(21.3)$ & $41(18.2)$ & $57(25.3)$ & $225(100.0)$ \\
\hline - Females & $44(37.9)$ & $29(25.0)$ & $19(16.4)$ & $24(20.7)$ & $116(100.0)$ \\
\hline 4. Chi-square statistic for gender significance & 1.47 & & & &
\end{tabular}

$(p=0.69)$

Table 5. Differences between learning variables and outcomes among different motivational profiles.

$\begin{array}{llllll}\text { HIHC HILC LIHC } & \text { LILC } & F & P- & \text { Eta }\end{array}$

\begin{tabular}{|c|c|c|c|c|c|c|c|c|c|c|c|}
\hline & Mean & SD & Mean & SD & Mean & SD & Mean & SD & & value & Squared \\
\hline Intrinsic motivation & 4.29 & 0.3 & 4.19 & 0.26 & 3.69 & 0.37 & 3.53 & 0.42 & 114.6 & 0 & 0.503 \\
\hline \multicolumn{12}{|l|}{$(n=341$, scale scores: $1-5)$} \\
\hline Controlled motivation & 4.13 & 0.34 & 3.09 & 0.48 & 4.04 & 0.29 & 3.09 & 0.49 & 178.9 & 0 & 0.612 \\
\hline \multicolumn{12}{|l|}{$(n=341$, scale scores: $1-5)$} \\
\hline Deep strategy & 2.97 & 0.58 & 3.01 & 0.57 & 2.92 & 0.55 & 2.75 & 0.49 & 3.5 & 0.016 & 0.03 \\
\hline \multicolumn{12}{|l|}{$(n=337$, scale scores: $1-5)$} \\
\hline Surface strategy & 3.28 & 0.69 & 3.19 & 0.64 & 2.95 & 0.62 & 2.95 & 0.58 & 5.8 & 0.001 & 0.049 \\
\hline \multicolumn{12}{|l|}{$(n=337$, scale scores: $1-5)$} \\
\hline Mixed strategy & 2.3 & 0.55 & 2.35 & 0.79 & 2.67 & 0.75 & 2.48 & 0.66 & 4.4 & 0.005 & 0.038 \\
\hline \multicolumn{12}{|l|}{$(n=337$, scale scores: $1-5)$} \\
\hline Academic performance & 66.96 & 4.73 & 67.17 & 5.04 & 64.42 & 5.98 & 65.38 & 4.08 & 4.8 & 0.003 & 0.046 \\
\hline$(\mathrm{n}=301$, marks in $\%)$ & & & & & & & & & & & \\
\hline
\end{tabular}


The present study enrolled 346 students. The study tried to find out the motivational profiles among the medical students and how these motivational profiles associated with academic achievements among them. To our knowledge, motivation profile among the medical students is the first of its kind done in this country.

In the present study, males represented more than the female. It was seen that gender difference is significantly high in females than in the males $(p=0.05)$ for the intrinsic motivation. However, there was no significant difference between the genders in the controlled motivation group. This is in contrast to the study done by Kusurkar et $\mathrm{al}^{10}$ where intrinsic motivation was found to be statistically not significant, while males had significantly more controlled motivation than the females. Study done among the Swiss medical students found that women plan their career more purposefully than men. ${ }^{11}$ The results also indicated that extrinsic career motivation predict advanced academic achievement, whereas self-esteem and intrinsic career motivation influence the choice of specialty. Association of gender with motivation has been shown in various other studies as well. ${ }^{12,13}$

Among the most common reasons for enrollment in this study was found to be contribution to welfare of society (38.6\%) followed by self achievement (37.8\%). This finding is slightly different to the finding study done in Madhya pradesh in India by Diwan et $\mathrm{al}^{14}$ where service motive accounted for $20 \%$, while personal ambition and parental desire accounted for $23 \%$ each. Another study done in Nepal by Bruce et $\mathrm{al}^{15}$ found that career choices of medical students was determined by the personal interest, social prestige and passion to serve the sick.

Similarly in this study we found out that the motivation profiles of students had effect on the academic learning strategies. It implies that interest plus status motivated and interest motivated students know when and where to apply both deep and surface strategies to achieve good result. Mixed strategy towards study seemed to have pursued more by status motivated and low motivation students as compared to interest motivated and interest plus status motivated students. Significant differences in mixed strategy towards study were observed between HIHC and LIHC, HILC and LIHC clusters.

A study done by Moulaert in Netherland found that positive correlations between aspects of deliberate practice (self-study, study resources, planning, study style and motivation) and good study achievements. ${ }^{16}$ One of the strength of this article is that we have seen motivational profiles among different subgroup and the learning outcomes.
Motivational theories state that intrinsic motivation is positively associated with academic performance. ${ }^{17}$ Intrinsic motivations were significantly and positively correlated with the deep strategy towards study and the academic performance. This study finding is similar to the study done by Kim et $\mathrm{al}^{18}$ where GPA performance was higher in the intrinsically motivated group. Similarly study done by Kursurkar et al. in the Dutch students showed interest-motivated students (HILC) had significantly more deep study strategy $(p<0.001)$, self-study hours $(p<0.05)$ and higher GPAs $(p<0.001) .{ }^{10}$ In another study , Sorbal ${ }^{19}$ reflected higher levels of autonomous motivation than controlled motivation. It showed that there is significant association of autonomous motivation with higher levels of meaning orientation, reflection in learning, academic achievement, cross-year peer-tutoring experience, and intention to continue with studies.

We found in this study that interest-status motivation (HIHC) and interest motivation (HILC) did not have much difference regarding deep strategy and surface strategy in learning. However it was quite different compared to low motivation (LILC) and status motivation (LIHC). This finding was similar with the study done by Vansteenkiste et al. ${ }^{20}$ along with Kusurkar et al. ${ }^{10}$ thus supporting the study findings from this study.

One of limitation of this study is that sample has been collected only from a single institution, which is private. It will be interesting to compare with the government institutions and how motivation profiles differ between two groups. Also it will be interesting to see how graduated and post graduate students differ with the motivational category.

Since the theoretical basis and hypotheses of our study does not include a motivation subscale of AMS, we did not use this for calculation.

\section{CONCLUSIONS}

The interest status motivated and interest-motivated medical students were associated with good deep and surface study strategy and good academic performance. Least desirable learning behaviors were associated with the Low-motivation (LILC) and status-motivated profiles (LIHC). Hence it could be stated that motivation is important required component for good learning outcomes for medical students. Motivational studies are limited in the developing countries, where prestige associated with the profession is hugely attached. Given this scenario, understanding motivational profiles and their association with learning outcomes will provide support for the future research for mentoring of the 
medical students and seeing the outcome. The possibility of conducting longitudinal research will give more idea about motivation and its further relation with learning outcomes and academic performances.

\section{REFERENCES}

1. Ryan RM, Deci EL. Intrinsic and Extrinsic Motivations:

Classic definitionsand new directions.Contemp Educ Psychol. 2000; 25:54-67. [Science Direct]

2. Vansteenkiste M, Lens W, Deci EL. Intrinsic Versus Extrinsic Goal Contentsin Self-Determination Theory: Another Look at the Quality of Academic Motivation. Educ Psychol. 2006; 41(1):19-31.[Full Text]

3. Pintrich P, Shonk D,Angizeshdartaalimvatarbieyat. In: Shahraray M, translator; Tehran: Elm; 2007.

4. Vansteenkiste M, Sierens E, Soenens B, Luyckx K, Lens W. Motivational Profiles From a Self- Determination Perspective: The Quality of Motivation Matters. J Educ Psychol 2009,101(3):671-688.[Full Text]

5. Violato C, Hecker KG. How to use structural equation modeling in medical educationresearch: A brief guide. Teaching and Learning in Medicine. 2007; 19(4):362371[Full Text]

6. Kline RB. Principles and practice of structural equation modeling (3rd ed.). NY: The Guillford Press. 2011.

7. Vallerand RJ, Pelletier LG, Blais MR, Briere NM, Senecal $C$, Vallieres EF. On the assessment of intrinsic, extrinsic and amotivation in education: Evidenceof concurrent and construct validity of the Academic Motivation Scale.Educ Psychol Meas. 1993; 53:159-172.[Full Text]

8. Kusurkar R, Croiset G, Kruitwagen CLJJ, Ten Cate TJ. Validity evidence for the measurement of the strength of motivation for medical school. Adv Health Sci Educ. 2011; 16:183-195.[Full Text]

9. Biggs J, Kember D, Leung DYP. The revised two-factor Study Process Questionnaire: R-SPQ-2F. Br J Educ Psychol. 2001; 71:133-149.[Full Text]

10. Kusurkar RA, Croiset G, Galindo-garré F, Cate OT. Motivational profiles of medical students: Association with study effort , academic performance and exhaustion. 2013.[Full Text]

11. Buddeberg-Fischer B, Klaghofer R, Abel T, Buddeberg C. The influence of gender and personality traits on the career planning of Swiss medical students. Swiss Med Wkly. Switzerland. 2003;133(39-40):535-40.[Full Text]

12. Heiligers PJ. Gender differences in medical students' motives and career choice. BMC Med Educ [Internet]. 2012;12(1):82. [Pub Med]

13. Kusurkar R, Croiset G, Cate OT. Implications of gender differences in motivation among medical students. Med Teach [Internet]. 2013;35(5):173-4.[Pub Med]

14. Pradesh M. Indian medical students in public and private sector medical schools: are motivations and career aspirations different? - studies from. 2013.

15. Hayes BW, Shakya R. Career choices and what influences Nepali medical students and young doctors: a cross-sectional study. Hum Resour Health [Internet]. 2013;11(1):1. [Bio Med]

16. Moulaert V, Verwijnen MGM, Rikers R, Scherpbier AJJA. The effects of deliberate practice in undergraduate medical education. Med Educ. England. 2004;38(10):1044-52. [Full Text]

17. Ryan R, Deci E. Intrinsic and Extrinsic Motivations: Classic Definitions and New Directions. Contempl Educ Psychol. 2000;25(1):54-67. [Science Direct]

18. Kim K, Hwang JY, Kwon BS. Differences in medical students ' academic interest and performance across career choice motivations. 2016;52-5.[Full Text]

19. Sobral DT. What kind of motivation drives medical students' learning quests? Med Educ England. 2004;38(9):950-7. [Full Text]

20. Vansteenkiste M, Sierens E, Soenens B, Luyckx K, Lens W. Motivational profiles from a self-determination perspective. The quality of motivation matters. J Educ Psychol. 2009;101(3):671-88.[Full Text] 